\title{
BDA hosts roundtable on care home crisis
}

Leaders from across health and social care joined with patient group and local authority leaders at the British Dental Association's (BDA's) London HQ on 1 July 2019 to build on the momentum from the launch of the CQC's damning report 'Smiling matters: oral health care in care homes.'

The report found systemic failure to provide plans, policies or adequate provision for care home residents.

Participants in the roundtable event included Age UK, the Alzheimer's Society, the National Care Association, the Relatives and Residents Association, and the British Society of Dental Hygiene and Therapy.

Charlotte Waite, Chair of the BDA's England Community Dental Services Committee, said: 'The crisis in our care homes has brought together colleagues from across the dental team, with officials and regulators, care providers and patient groups.

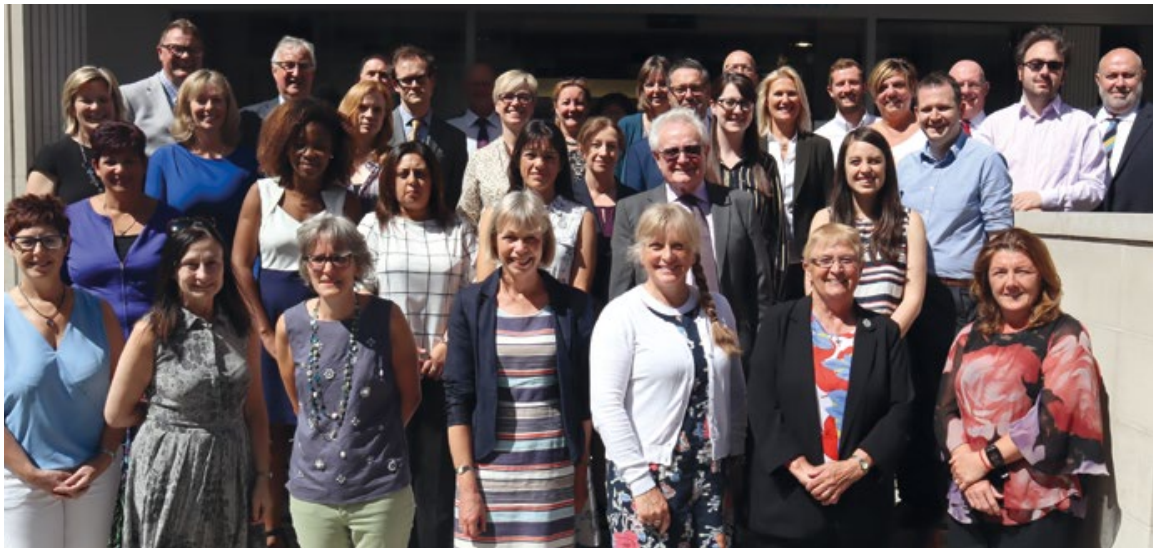

Participants in the roundtable event on oral healthcare in care homes, at the BDA in Wimpole Street

'We stand united in common cause, to find solutions to a problem impacting on some of the most vulnerable people in our society. We've seen the evidence, now it is our responsibility to turn recommendations into reality.

'Together we are determined to show leadership on what remains just one of the missing pieces in care plans, policies and provision.

\section{References}

1. Care Quality Commission. Smiling Matters: oral 2019. Available at: https://www.cqc.org.uk/publications/major-report/smiling-matters-oral-health-carecare-homes (accessed July 2019). health care in care homes. Last updated 25 June

\section{Here has been an advertisement.}

\section{SPRINGERNATURE}

